\title{
Gold Nanoparticles in Stereotactic Radiosurgery for Cerebral Arteriovenous Malformations
}

\author{
Frederik Vernimmen ${ }^{*}$, Mikhail L. Shmatov ${ }^{2}$ \\ ${ }^{1}$ Department of Radiation Oncology, Cork University Hospital, Cork, Ireland \\ ${ }^{2}$ Ioffe Institute, St. Petersburg, Russia \\ Email: *Frederik.Vernimmen@hse.ie
}

Received 13 May 2015; accepted 7 July 2015; published 13 July 2015

Copyright (C) 2015 by authors and Scientific Research Publishing Inc.

This work is licensed under the Creative Commons Attribution International License (CC BY). http://creativecommons.org/licenses/by/4.0/

(c) (i) Open Access

\section{Abstract}

Objective of the study: To explore the potential for therapeutic gain with gold nanoparticles in arteriovenous malformation radiosurgery based on their interaction with photons and protons. Study methods: Radiation dose enhancement resulting from the interaction of gold nanoparticles with irradiation ranging from kilovoltage to megavoltage photons and protons was researched in the literature. The role of angiogenesis and its regulation via vascular endothelial growth factors and cell membrane receptors, especially for endothelial cells in arteriovenous malformations, was investigated as a way for selective arteriovenous malformation deposition. Results: Radiation dose enhancement with gold nanoparticles is described in the literature but has so far only been investigated for its potential in treating malignancies. Because of the high atomic number of gold $(Z=79)$, dose enhancement occurs with photons mainly based on secondary photon and Auger electron production and the dose enhancement factor is the highest for irradiation with kilo voltage photons. Dose enhancement happens with megavoltage photons also but to a lesser extend and is mainly due to the ionization of gold by secondary photons and electrons generated by the megavoltage photons passing through tissue. The range of the secondary photo electrons emitted by gold is sufficient to cover the entire endothelial cell content. Protons interact with the production of Auger electrons which have a very short range, insufficient to cover the entire contents of endothelial cells, but sufficient to cause a high cell membrane dose for membrane located gold nanoparticles (AuNPs). Arteriovenous malformations are dynamic entities with angiogenesis taking place. This is reflected by a different expression of angiogenic receptors on the membrane of arteriovenous malformation endothelial cells compared to normal brain blood vessels, thereby opening the opportunity for selective deposition of such particles. For the use in proton therapy a new definition for the dose enhancement factor describing the local effect of nanoparticles is proposed. Conclusion: The concept of nanoparticle enhanced radiosurgery for arteriovenous malfor-

*Corresponding author.

How to cite this paper: Vernimmen, F. and Shmatov, M.L. (2015) Gold Nanoparticles in Stereotactic Radiosurgery for Cerebral Arteriovenous Malformations. Journal of Biomaterials and Nanobiotechnology, 6, 204-212.

http://dx.doi.org/10.4236/jbnb.2015.63019 
mations by selective deposition of gold nanoparticles is a novel approach. The local dose enhancement opens the way for therapeutic gain which in turn could lead to improved obliteration rates and/or a shorter latent period.

\section{Keywords}

\section{Nanoparticle, Arteriovenous Malformation, Radiosurgery, Dose Enhancement}

\section{Introduction}

Radiosurgery is a well established therapeutic option for cerebral Arterio Venous Malformations (AVM), but the successful outcome is influenced by the AVM volume, its location, and the radiation dose that can safely be administered. There is always a latent time post radiosurgery until complete obliteration occurs. This latent time occurs with photons as well as with proton irradiation. Therapeutic response is dose related with higher doses increasing the obliteration rate. Only complete obliteration is considered as a cure, but this is difficult to achieve for large AVMs with present radiosurgical techniques. To improve the results for large AVMs, the use of gold nanoparticles as radiation dose enhancers is explored.

The use of gold in medicine can go back to the ancient Egyptians but its use in modern medicine started in the 19 century with Robert Koch using it as a bacteriostaticum for the tubercle bacillus. Subsequently Laude used gold to treat the symptoms of Rheumatoid Arthritis (RA) in 1927, and Forestier showed beneficial results in RA patients [1]. Although the use of gold in clinical practice has declined significantly over the last 2 decades, the rapidly expanding science of nanoparticles (NP) has revived interest in gold (Au) in the form of NPs. Gold nanoparticles (AuNP) are only one form of nanoparticles that have been investigated as carriers for therapeutic agents and for diagnosis, the field of "Theranostics" [2]. Nanoparticles exert their effect by either entering the cell or by attaching to the cell membrane surface, and have been extensively studied for their oncology treatment potential [3]-[22]. By definition nanoparticles range in size from $1 \mathrm{~nm}=1 \times 10^{-9} \mathrm{~m}$ to $100 \mathrm{~nm}$ [12]. A large number of substances can be made into NPs, and their medical use includes drug delivery, photo thermal agents, contrast agents and radio sensitizers [13]. Metallic NPs can be made from a number of metals amongst them gold. The pharmacokinetics of metallic NPs depend on the particle type, size, surface charge, surface coating, protein binding, exposure route, and dose [14]. Absorption through skin or after oral administration is poor and the most effective way of administration is by intravenous injection [14].

AuNPs can be manufactured into a variety of shapes such as nanospheres, nanorods, nanobelts, nanocages, nanoprisms and nanostars [4]. The chemical, optical and electromagnetic properties of AuNPs are strongly influenced by their size and shape. Differences in size, shape, and surface properties are manipulated for specific therapeutic purposes [15]. Gold is very biocompatible and especially attractive as a radiation enhancer due to its high Z, equaling 79, a favorable characteristic for interaction with photons, electrons and protons. This interaction generates much localized secondary radiation. The resulting Dose Enhancement Factor (DEF) varies with the energy and type of the incoming radiation and is most pronounced with kilo voltage photons, but happens also with Mega Voltage (MV) photon radiation and with protons [6]-[11] [21] [22]. Here, for the sake of brevity, we use the term "DEF" to describe the physical dose enhancement factor; such terminology was used by Robar et al. [24] and Lin et al. [21]. Gold nanoparticles deposited in the AVM at the time of irradiation have the potential to improve the outcome of AVM radiosurgery based on this localized radiation dose enhancement effect. A reduced latent time due to this additional dose would have a significant clinical impact seeing that patients are at risk for a hemorrhage as long as the AVM is not completely occluded. The rationale for therapeutic gain in AVM radiosurgery by using AuNPs is considered below.

\section{Study Methods}

The literature was researched (PubMed) using the keywords: nanoparticles, radiosensitization, photon, proton beam, and angiogenesis. The results of these searches were used to compile the theoretical basis for the novel concept of "nanoparticle enhanced radiosurgery". The role of angiogenesis and its regulation via vascular endothelial growth factors acting on cell membrane receptors was investigated as a method to selectively concentrate 
gold nanoparticles in the AVM. Analytical calculations of DEF in the vicinity of AuNP were performed. In these calculations, the computer simulation results available in literature were used.

Gold nanoparticles as radiation dose enhancers

a) Photon irradiation

For X-rays, metallic NP radio sensitization results mainly from the photoionization of the metal [2] [3] [7] [10] [16]. This photoionization generates photo electrons and Auger electrons. Of greater clinical value is the radio sensitization with MV photons and although the ratios of the interaction cross-sections of Au and tissue components with such photons are much smaller than those for keV X-rays, Monte Carlo calculations have nevertheless shown a dose enhancement for MV photons. The enhancement is mainly due to the ionization of Au by the secondary photons and electrons generated by the MV photons passing through tissue [17] [18]. The results of some of the experiments indicate that catalytic [19] and/or biological [20] effects may also be important for photon irradiation.

b) Proton irradiation

A radiation enhancing effect also takes place with proton beams [11] [21] [22] [24] [25]. The proton-AuNP interaction mainly produces Auger electrons with a very short range forming a dense cloud in the immediate vicinity of the surface of the AuNP [21] [22]. Compared to irradiation with photons, interaction with protons produces similar secondary doses within the first $10 \mathrm{~nm}$ from the surface of the AuNP, but tapers off quickly beyond that range and hence the "sphere of DEF" resulting from a proton-AuNP interaction has only an enhancing effect when the AuNP is either close to the cell's nucleus or in very close contact with the cell membrane [21]. The features of motion and distributions of chemically and, as a result, biologically active particles, arising in the vicinities of nanoparticles, may also be important. These features can have a strong effect on disappearance, or, in other words, recombination of such particles soon after their production [26] [27]. For example, the ionized nanoparticle will emit several electrons and, therefore, will acquire the positive electric charge of several absolute values of electron charge [28]. The electric field of this charge may separate positive and negative ions created in the tissue by the electrons emitted by the nanoparticle, thereby suppressing partly their recombination. As a result, at least the lifetimes of the positive ions arising in the vicinity of the nanoparticle will probably increase and, therefore, the biological effect of these ions.

\section{Results}

Theoretical calculations

As mentioned earlier the overall AuNP's radiosensitizing effect is determined by: size, concentration, radiation energy, catalytic, and biological factors. For dose enhancement with photons, Brun et al. [29] studied some of these parameters and found that the best results were achieved when using large AuNPs (50 nm), at a high molar concentration and with $50 \mathrm{kV}$ photons. This combination showed a 6-fold dose enhancement over controls. The strongest enhancement is with $\mathrm{kV}$ energies with theoretical calculated DEF's in the range of 1.6 to 7.2 [30].

The secondary radiation produced by the interaction between photons and AuNPs consists mostly of photoelectrons and their range extends up to hundreds of microns, well beyond the dimensions of the individual endothelial cells. Only a small fraction of their energy is deposited in the immediate vicinity of the surface of the NP. Small amounts of Auger electrons of low energy are also produced with a range of $<1 \mu \mathrm{m}$ and hence most of their energy is deposited very near the surface of the NP. Additional factors that affect indirectly the AuNPphoton interaction are the field size of the beam and the use of flattening free filters. Small field sizes reduce the dose enhancing effect as they contain a lower component of "soft X-rays". For field sizes smaller than $3 \times 3 \mathrm{~cm}^{2}$ the primary beam is the main contributor of dose [31] and hence one would not expect a difference between treatment with very small beams (Gamma knife ${ }^{\circledR}$ or Cyberknife ${ }^{\circledR}$ ) versus Linac micro-multi leaf beams. The presence of a higher component of "soft X-rays" in flattening filter free beams also enhances the DEF [31].

For dose enhancement with protons, studies of DEF have begun fairly recently. Lin et al. (21) theoretically calculated a DEF of up to 14 and found it to be independent of proton energy $\varepsilon_{p}$ (at $10 \mathrm{MeV} \leq \varepsilon_{p} \leq 150$ $\mathrm{MeV}$ ), in contrast to photons. Wälzlein et al. [22] simulated irradiation of water, containing metallic NPs ( $\mathrm{Au}, \mathrm{Pt}$, Fe, Gd, Ag), with $80 \mathrm{MeV}$ protons. Their results and the definition of Lin et al. correspond to a DEF of up to two in the vicinity of the NP within a radial distance of $18 \mathrm{~nm}$ from the surface of the NP $(\mathrm{r}=22 \mathrm{~nm})$. For a smaller NP $(r=2 \mathrm{~nm})$ this radius fell to $5 \mathrm{~nm}$. 
The secondary radiation produced by the interaction of protons on AuNPs consists of Auger electrons. Gao and Zheng [32] studied the influence of size of the AuNP and energy of the protons (20-50-100 MeV) on the secondary electron production, and showed that this production increased with decreasing proton energy and increasing size of the NP. The kinetic energy of the electrons increased with increasing proton beam energy.

Dose enhancement definitions. For protons, Lin et al. [21] defined the DEF as the ratio $D_{G N P} / D_{W N P}$, where $D_{G N P}$ was the average dose deposited in water by electrons emitted by the gold nanoparticle after passage of one proton through it and $D_{W N P}$ was the average dose deposited in water by electrons emitted by a similar sized water nanoparticle after passage of one proton through it. Note that this DEF definition of Lin et al. is not similar to those introduced by other authors earlier. For example, Robar et al. [23] analyzed the biological effect of the high-energy photons and defined the DEF as the ratio of the average dose in the tumor region with and without contrast media (CM). The physically similar definition of DEF for proton therapy with the use of AuNPs has the form DEF $=\left(D_{\text {pure }}+D_{G N P}-D_{W N P}\right) / D_{\text {pure }}$, where $D_{\text {pure }}$ is the dose deposited in pure water by the proton beam with the time integrated flux $F=1 /\left[\pi\right.$ (nanoparticle radius) $\left.{ }^{2}\right]$ corresponding to passage of one proton through the nanoparticle. Lin et al. [21] simulated the irradiation of nanoparticles with a radius of $25 \mathrm{~nm}$; for such nanoparticles:

$$
D_{\text {pure }}[\mathrm{Gy}] \approx 8.16 \times S_{w}\left[\mathrm{MeV} \times \mathrm{cm}^{2} / \mathrm{g}\right],
$$

where $S_{w}$ is the stopping power of water. Using the values of $D_{G N P}$ and $D_{W N P}$ from the paper by Lin et al. [21] and the data of Berger et al [33] on $S_{w}$, we obtain that the results of the computer simulation of Lin et al. correspond to a DEF of about 1.06 at the distance of $1 \mathrm{~nm}$ from the nanoparticle surface with lower DEF values at greater distances.

In vivo results

Studies on tumor growth retardation in mice after proton irradiation + AuNPs confirm a major benefit from this combination. Kim et al. [11] used gold and iron nanoparticles in proton therapy of tumors in mouse legs and flanks. For the experiments with tumors in mouse legs, the plateau part of the beam was used and both the proton kinetic energies $\varepsilon_{k}$ and the efficiency of the use of NPs were higher. This and the increases in the ratios of the stopping powers of gold and iron to $S_{w}$ with $\varepsilon_{k}$ [33] indicate that the efficiency of the use of AuNPs and other NPs in proton therapy increases with $\varepsilon_{k}$ [34]. This improved radiobiological effect was interpreted as the result of an increase in secondary electron production and an increase in Reactive Oxygen Species (ROS) [11]. The catalytic and/or biological effects as mentioned earlier for photons may also play a role in proton therapy. The examples of Dose Enhancement Factor results for endothelial cells and for tissue in close proximity of the AuNP are presented in Table 1.

Table 1. Dose enhancement factors and $D_{G N P} / D_{W N P}$.

\begin{tabular}{|c|c|c|c|c|c|}
\hline Authors & NP size & Concentration & Model & Energy & DEF or $D_{G N P} / D_{W N P}$ \\
\hline Ngwa, W. et al.[53] & $1.9 \mathrm{~nm}$ & $1-7$ mg/g & calculated & $100 \mathrm{kV}$ & $1.3-3.26$ \\
\hline \multirow[t]{2}{*}{ Amateo, E. et al.[30] } & $\mathrm{n} / \mathrm{s}^{\mathrm{a}}$ & $10 \mathrm{mg} / \mathrm{ml}$ & calculated & $150 \mathrm{kV}$ & 1.6 \\
\hline & & $200 \mathrm{mg} / \mathrm{ml}$ & calculated & $150 \mathrm{kV}$ & 6.5 \\
\hline \multirow[t]{2}{*}{ Rahman, W. et al.[54] } & $1.9 \mathrm{~nm}$ & $0.197 \mathrm{mg} / \mathrm{ml}$ & In vivo & $40 \mathrm{kV}$ & 3.47 \\
\hline & & & & $100 \mathrm{kV}$ & 1.35 \\
\hline \multirow[t]{3}{*}{ Berbeco, R. et al.[18] } & $100 \mathrm{~nm}$ & $30 \mathrm{mg} / \mathrm{g}$ & calculated & $6 \mathrm{MV}$ & 1.7 \\
\hline & & $7 \mathrm{mg} / \mathrm{g}$ & calculated & $6 \mathrm{MV}$ & 1.2 \\
\hline & & $140 \mathrm{mg} / \mathrm{g}$ & calculated & $6 \mathrm{MV}$ & 4.4 \\
\hline Detappe, A. et al.[31] & $100 \mathrm{~nm}$ & $30 \mathrm{mg} / \mathrm{ml}$ & calculated & $6 \mathrm{MV}$ & 2.1 \\
\hline \multirow[t]{2}{*}{ Wälzlein, C. et al.[22] } & $2 \& 22 \mathrm{~nm}$ & $\mathrm{n} / \mathrm{a}^{\mathrm{b}}$ & Calculated & proton & $\leq 2^{\mathrm{c}}$ \\
\hline & & & & $80 \& 300 \mathrm{MeV}$ & \\
\hline
\end{tabular}

a: not stated; b: not applicable; c: $D_{G N P} / D_{W N P}$ in the vicinity of NP. 


\section{Discussion}

The best treatment for cerebral AVMs remains microsurgery because it offers immediate protection against hemorrhagic events, and offers a cure although recurrences have been documented [35] [36]. Radiosurgery is a well established alternative to surgery with the best results being obtained in small AVMs located in non-eloquent areas. Therapeutic response is dose related with higher doses increasing the obliteration rate. However radiation doses successful for small AVMs, become increasingly difficult to apply safely with increasing AVM volume, greater shape complexity and eloquent location.

In radiosurgery of AVMs the primary target are the endothelial cells. Their cell death triggers the events that lead to obliteration [37]. Endothelial cells are very flat, are about 1 - $2 \mu \mathrm{m}$ thick and some $10-20 \mu \mathrm{m}$ in diameter with a very thin cell membrane $(7-10 \mathrm{~nm})$ [18]. Exploiting the DEF resulting from the interaction with radiation and AuNPs has the potential to achieve therapeutic gain with AuNPs in AVM radiosurgery. However in order to achieve this, selective AVM endothelial cell AuNP accumulation is essential. The biodistribution of unmodified AuNPs is dependent on their size. Small AuNPs (5 nm) can cross the blood brain barrier [38]. AuNPs of $11 \mathrm{~nm}$ do not cross the normal blood brain barrier but are able to cross the blood tumor barrier [39]. AuNPs of $50 \mathrm{~nm}$ are the most readily absorbed by cells and provide the best results in terms of secondary radiation when exposed to photons [1] [39]. In tumors passive selective accumulation can be achieved by AuNPs entering the tumor tissue through "leaky" abnormal tumor blood vessels. This accumulation can be further improved on by linking AuNPs to specific tumor antigens such as Herceptin ${ }^{\circledR}$ [39].

Circulating "naked" AuNPs can enter AVM as well as normal endothelial cells and although an intracellular location is desirable, this approach offers little potential for achieving a differential AuNP concentration between the AVM and normal vessel endothelial cells. On the other hand, opting for a luminal cell membrane location by linking the AuNP to a membrane receptor antibody makes selective AVM endothelial cell adherence possible [4] [40]. Endothelial cell membrane receptors have been studied extensively because angiogenesis is driven by endothelial cells stimulated by receptor activation [40]. Angiogenesis and its blockage has been the focus of intense study in oncology resulting in a multitude of drugs now available to treat a variety of tumors. A human IgG1 mAb (Ramucirumab ${ }^{\circledR}$ [IMC-1121B]) that selectively binds to VEGFR2 receptors and blocks the VEGFR2 signaling pathway has been developed as an angiogenesis inhibitor for cancer therapy and has shown clinical activity in tumors, including gastric cancer, with a favorable toxicity profile [41]. Ramucirumab ${ }^{\circledR}$ has been FDA approved for patients with advanced gastro esophageal cancer [42]. A VEGFR2 antibody-AuNP complex attaching itself on the VEGFR2 cell membrane receptors can concentrate AuNPs on the luminal endothelial cell surface. VEGFR2 receptor membrane distribution has been studied using an anti-VEGFR2-albuminGd-DTPA probe whereby the receptor distribution in tumors could be assessed [43]. Human brain AVM endothelial cells express VEGFR2 differently than normal brain blood vessel endothelial cells, and an over expression of VEGFR2 receptors is generally found [44]-[46]. Other endothelial receptors have also been studied; the Tie receptor is up regulated in vascular malformations compared to normal vessels [47], and ephrinB2 is strongly present in the arteries of AVM in humans, but not on endothelial cells from the normal superficial temporal artery [48].

Therefore AuNP-receptor antibody complexes attached on the luminal cell membrane surface of AVM endothelial cells, combined with the range of the secondary radiation generated, exposes the intracellular contents to a "sphere of DEF" when the AuNP is irradiated. The distribution of a multitude of AuNPs on the cell membrane, each with its sphere of dose enhancing, and the geometric overlap of such spheres can therefore cause significant damage to the cells.

This effect would be influenced by the irradiation modality used. As described above, for photons the range of the secondary radiation originating from AuNPs located on the membrane surface is more than sufficient to cover the entire volume of the endothelial cell and interact with all its contents, amongst others the DNA in the nucleus (Figure 1). For protons the sphere of DEF is very small and does not cover the entire volume of the cell. For an AuNP located on the cell surface, its effects are limited to the cell membrane itself (Figure 2). This does not necessarily preclude causing lethal cell damage, because although for conventional dose/fractionation schedules the radiobiological effect is governed by DNA damage in the cell nucleus, for high dose/fraction schedules other mechanisms causing cell apoptosis are involved. A cell membrane initiated effect, independent of nuclear events, has been described whereby activation of the acid sphingomyelinase/ceramide pathway occurs after doses $>10 \mathrm{~Gy}$, leading to apoptotic endothelial cell death [49]. Therefore protons could, in spite of the small radius of 


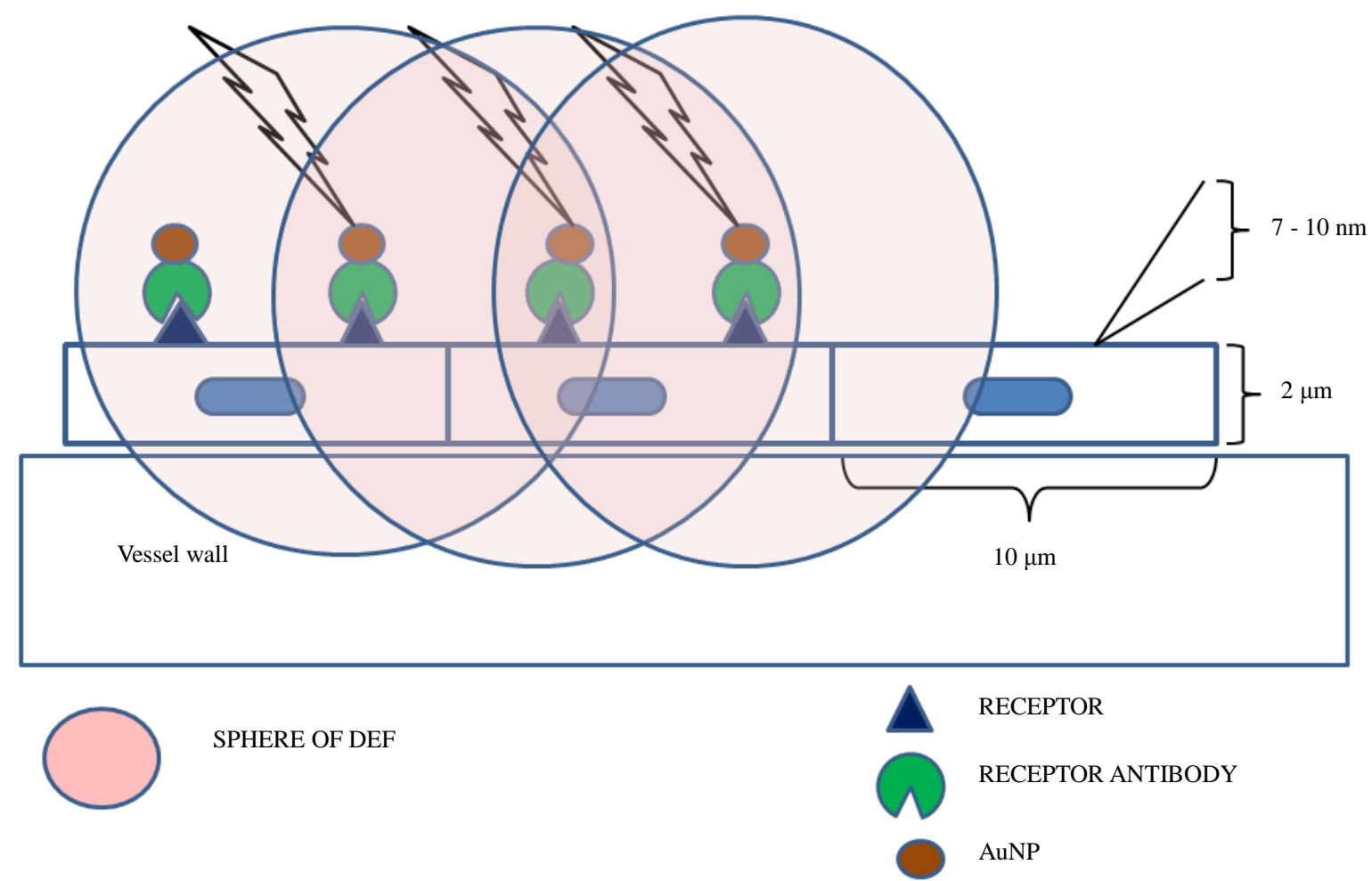

Figure 1. Diagram for photons showing that the sphere of dose enhancement for luminal located AuNPs reaches well beyond the endothelial cell structures, with overlap of neighboring spheres [not to scale].

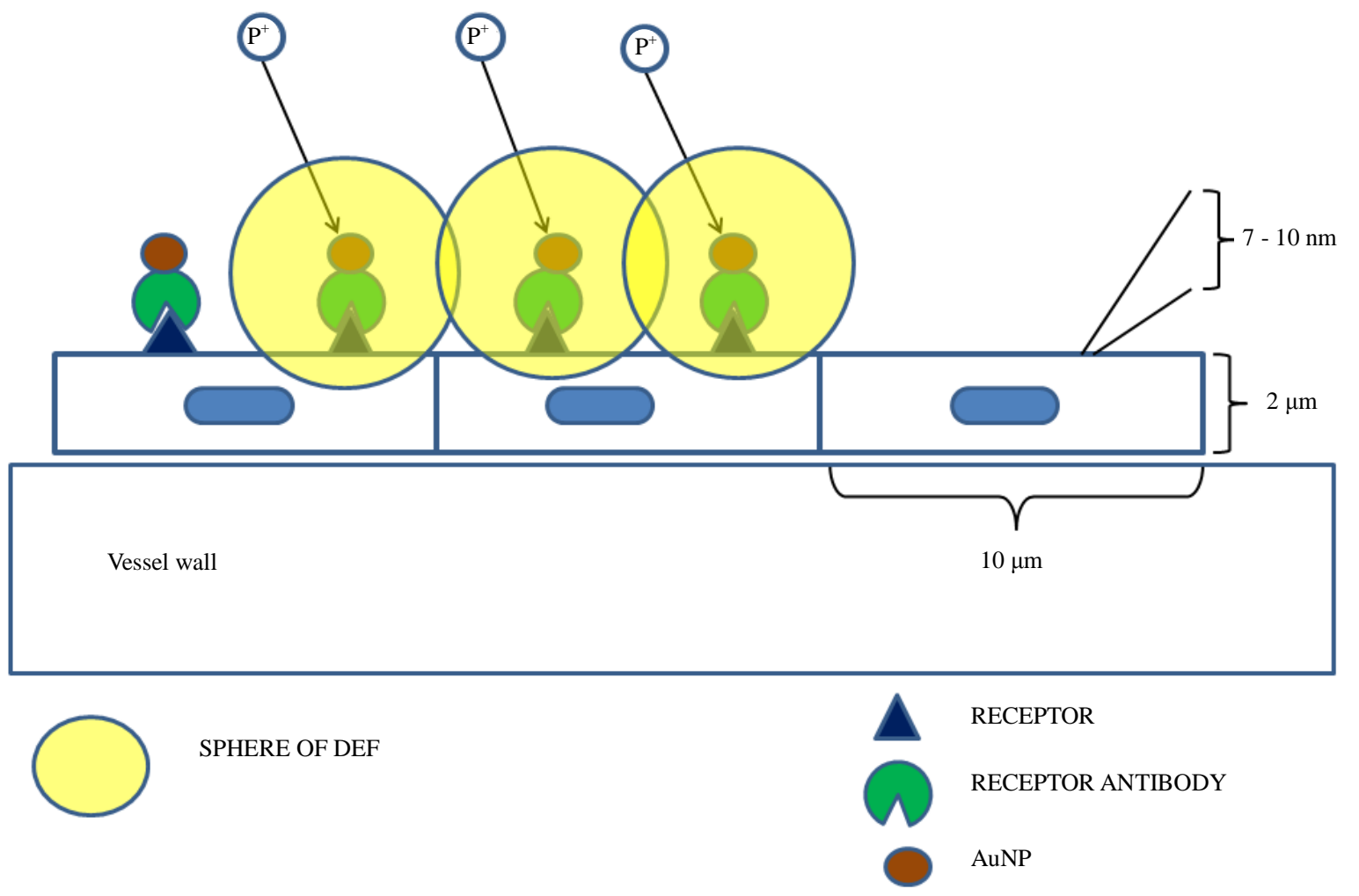

Figure 2. Diagram for protons showing the small sphere of dose enhancement insufficient to cover the entire endothelial cell content and with minimal overlap of individual spheres [not to scale]. 
their DEF sphere, still offer therapeutic gain with cell membrane located AuNPs on condition that a sufficiently high radiation dose is applied.

Of interest is also the observation that VEGFR2-antibodies on their own, when attached to the cell membrane receptors at the time of irradiation have a radio sensitization effect on endothelial cells [50].

The role of angiogenesis in AVMs and the potential role of anti-angiogenic therapy as a therapeutic intervention are under investigation [51] [52]. A VEGFR2 blockade achieved with antibody-AuNP complexes as described above has the potential to enhance the apoptotic processes in endothelial cells, thereby intensifying and speeding up the obliteration process. This would be of major clinical significance for patients not able to undergo surgery as they are at risk for a new hemorrhagic event during the post radiosurgery latent time period which lasts until the AVM is completely occluded.

\section{Conclusion}

The concept of nanoparticle enhanced stereotactic radiosurgery is new. By exploiting the role of angiogenesis in AVMs, possible mechanisms open up to selectively target AuNPs onto AVM endothelial cells. The presence of AuNPs at the time of irradiation creates a site specific dose enhancement within the AVM itself. This approach to improving AVM radiosurgical results needs further research, but if feasible, AuNPs would be worth their weight in gold.

\section{References}

[1] Thakor, A.S., Jokerst, J., Zaveleta, C., Massoud, T.F. and Gambhir, S.S. (2011) Gold Nanoparticles: A Revival in Precious Metal Administration to Patients. Nano Letters, 11, 4029-4036. http://dx.doi.org/10.1021/nl202559p

[2] Mieszawska, A.J., Mulder, W.J.M., Fayad, Z.A. and Cormode, D.P. (2013) Multifunctional Gold Nanoparticles for Diagnosis and Therapy of Disease. Molecular Pharmaceutics, 10, 831-847. http://dx.doi.org/10.1021/mp3005885

[3] Babaei, M. and Ganjalikhani, M. (2014) A Systematic Review of Gold Nanoparticles as Novel Cancer Therapeutics. Nanomedicine Journal, 1, 211-219.

[4] Cai, W.B., Gao, T., Hong, H. and Sun, J.T. (2008) Applications of Gold Nanoparticles in Cancer Nanotechnology. Nanotechnology, Science and Applications, 1, 17-32.

[5] Kumar, R., Korideck, H., Ngwa, W., Berbeco, R.I. and Sridhar, S. (2013) Third Generation Gold Nanoplatform Optimized for Radiation Therapy. Translational Cancer Research, 2, 228-239.

[6] Ngwa, W., Kumar, R., Sridhar, S., Korideck, H., Zygmanski, P., Cormack, R.A., et al. (2014) Targeted Radiotherapy with Gold Nanoparticles: Current Status and Future Perspectives. Nanomedicine, 9, 1063-1082. http://dx.doi.org/10.2217/nnm.14.55

[7] Hainfeld, J.F., Dilmanian, F.A., Slatkin, D.N. and Smilowitz, H.M. (2008) Radiotherapy Enhancement with Gold Nanoparticles. J Pharm Pharmacol, 60, 977-985. http://dx.doi.org/10.1211/jpp.60.8.0005

[8] Liu, C.J., Wang, C.H., Chen, S.T., Chen, H.H., Leng, W.H., Chien, C.C., et al. (2010) Enhancement of Cell Radiation Sensitivity by Pegylated Gold Nanoparticles. Physics in Medicine and Biology, 55, 931-945. http://dx.doi.org/10.1088/0031-9155/55/4/002

[9] Cooper, D.R., Bekah, D. and Nadeau, J.L. (2014) Gold Nanoparticles and Their Alternatives for Radiation Therapy Enhancement. Frontiers in Chemistry, 2, Article 86. http://dx.doi.org/10.3389/fchem.2014.00086

[10] Kwatra, D., Venugopal, A. and Anant, S. (2013) Nanoparticles in Radiation Therapy: A Summary of Various Approaches to Enhance Radiosensitization in Cancer. Translational Cancer research, 2, 330-342.

[11] Kim, J.K., Seo, S.J., Kim, H.T., Kim, K.H., Chung, M.H., Kim, K.R., et al. (2012) Enhanced Proton Treatment in Mouse Tumours through Proton Irradiated Nanoradiator Effects on Metallic Nanoparticles. Physics in Medicine and Biology, 57, 8309-8323. http://dx.doi.org/10.1088/0031-9155/57/24/8309

[12] Babaei, M. and Ganjalikhani, M. (2014) The Potential Effectiveness of Nanoparticles as Radiosensitizers for Radiotherapy. Bioimpacts, 4, 15-20.

[13] Kim, B.Y.S., Rutka, J.T. and Chan, W. (2010) Current Concepts Nanomedicine. New England Journal of Medicine, 363, 2434-2343. http://dx.doi.org/10.1056/NEJMra0912273

[14] Lin, Z., Monteiro-Riviere, N.A. and Riviere, J.E. (2015) Pharmacokinetics of Metallic Nanoparticles. Nanomed Nanobiotechnol, 7, 189-217. http://dx.doi.org/10.1002/wnan.1304

[15] Zhang, X. (2015) Gold Nanoparticles: Recent Advances in the Biomedical Applications. Cell Biochemistry and Bio- 
physics, Epub ahead of publication.

[16] Hossain, M. and Ming, S. (2012) Nanoparticle Location and Material Dependent Dose Enhancement in X-Ray Radiation Therapy. The Journal of Physical Chemistry C: Nanomater Interfaces, 116, 23047-23052. http://dx.doi.org/10.1021/jp306543q

[17] McMahon, S.J., Hyland, W.B., Muir, M.F., Coulter, J.A., Jain, S., Butterworth, K.T., et al. (2011) Nanodosimetric Effects of Gold Nanoparticles in Megavoltage Radiation Therapy. Radiotherapy and Oncology, 100, 412-416. http://dx.doi.org/10.1016/j.radonc.2011.08.026

[18] Berbeco, R.I., Ngwa, W. and Makrigiorgos, G. (2011) Localized Dose Enhancement to Tumour Blood Vessel Endothelial Cells via Megavoltage X-Rays and Targeted Gold Nanoparticles: New Potential for External Beam Radiotherapy. International Journal of Radiation Oncology, Biology, Physics, 81, 270-276. http://dx.doi.org/10.1016/j.ijrobp.2010.10.022

[19] Sicard-Roselli, C., Brun, E., Gilles, M., Baldacchino, G., Kelsey, C., McQuaid, H., et al. (2014) A New Mechanismfor Hydroxyl Radical Production in Irradiated Nanoparticle Solutions. Small, 10, 3338-3346. http://dx.doi.org/10.1002/smll.201400110

[20] Taggart, L.E., McMahon, S.J., Currell, F.J., Prise, K.M. and Butterworth, K.T. (2014) The Role of Mitochondrial Function in Gold Nanoparticle Mediated Radiosensitization. Cancer Nanotechnology, 5, 5. http://dx.doi.org/10.1186/s12645-014-0005-7

[21] Lin, Y., McMahon, S.J., Scarpelli, M., Paganetti, H. and Schuemann, J. (2014) Comparing Gold Nano-Particle Enhanced Radiotherapy with Protons, Megavoltage Photons and Kilovoltage Photons: A Monte Carlo Simulation. Physics in Medicine and Biology, 59, 7675-7689. http://dx.doi.org/10.1088/0031-9155/59/24/7675

[22] Wälzlein, C., Scifoni, E., Kramer, M. and Durante, M. (2014) Simulations of Dose Enhancement for Heavy Atom Nanoparticles Irradiated by Protons. Physics in Medicine and Biology, 59, 1441-1458. http://dx.doi.org/10.1088/0031-9155/59/6/1441

[23] Robar, J.L., Riccio, S.A. and Martin, M.A. (2002) Tumor Dose Enhancement Using Modified Megavoltage Photon Beams and Contrast Media. Physics in Medicine and Biology, 47, 2433-2449. http://dx.doi.org/10.1088/0031-9155/47/14/305

[24] Polf, J.C., Bronk, L.F., Driessen, W.H.P., Arap, W., Pasqualini, R. and Gillin, M. (2011) Enhanced Relative Biological Effectiveness of Proton Radiotherapy with Internalized Gold Nanoparticles. Applied Physics Letters, 98, Article ID: 193702. http://dx.doi.org/10.1063/1.3589914

[25] Le Sech, C., Kobayashi, K., Usami, N., Furusawa, Y., Porcel, E. and Lacombe, S. (2012) Comment on "Enhanced Relative Biological Effectiveness of Proton Radiotherapy in Tumor Cells with Internalized Gold Nanoparticles". Applied Physics Letters, 100, Article ID: 026101. http://dx.doi.org/10.1063/1.3675570

[26] Samuel, A.H. and Magee, J.L. (1953) Theory of Radiation Chemistry. II. Track Effects in Radiolysis of Water. The Journal of Chemical Physics, 21, 1080-1087. http://dx.doi.org/10.1063/1.1699113

[27] Byakov, V.M. and Stepanov, S.V. (2006) The Mechanism for the Primary Biological Effect of Ionizing Radiation. Uspekhi Fizicheskikh Nauk, 176, 487-506. (English citation: Physics-Uspekhi, 49, 469-487) http://dx.doi.org/10.3367/UFNr.0176.200605b.0487

[28] Porcel, E., Liehn, S., Remitta, H., Usami, N., Kobayashi, K., Furusawa, Y., et al. (2010) Platinum Nanoparticles: A Promising Material for Future Cancer Therapy? Nanothechnology, 21, Article ID: 85103. http://dx.doi.org/10.1088/0957-4484/21/8/085103

[29] Brun, E., Sanche, L. and Sicard-Roselli, C. (2009) Parameters Governing Gold Nanoparticle X-Ray Radiosensitization of DNA in Solution. Colloids and Surfaces B: Biointerfaces, 72, 128-134. http://dx.doi.org/10.1016/j.colsurfb.2009.03.025

[30] Amato, E., Italiano, A., Leotta, S., Pergolizzi, S. and Torrise, L. (2013) Monte Carlo Study of the Dose Enhancement Effect of Gold Nanoparticles during X-Ray Therapies and Evaluation of the Anti-Angiogenic Effect on Tumour Capillary Vessels. Journal of X-Ray Science and Technology, 21, 237-247.

[31] Detappe, A., Tsiamas, P. and Ngwa, W. (2013) The Effect of Flattening Filter Free Delivery on Endothelial Dose Enhancement with Gold Nanoparticles. Medical Physics, 40, Article ID: 031706.

[32] Gao, J. and Zheng, Y. (2014) Monte Carlo Study of Secondary Electron Production from Gold Nanoparticle in Proton Beam Irradiation. International Journal of Cancer Therapy and Oncology, 2, Article ID: 02025.

[33] Berger, M.J., Coursey, J.S., Zuker, M.A. and Chang, J. (2009) Stopping-Power and Range Tables for Electrons, Protons and Helium Ions. http://www.nist.gov/pml/data/star/

[34] Shmatov, ML. (2014) An Expected Increase in the Efficiency of the Antiproton and Pion Cancer Therapies at the Use of the Gold Nanopartices. Preprint of Ioffe Institute, Saint Petersburg, No. 1810. 
[35] Weil, A.G., Li, S. and Zhao, J.Z. (2011) Recurrence of a Cerebral Arteriovenous Malformation following Complete Surgical Resection: A Case Report and Review of the Literature. Surgical Neurology International, 2, 175. http://dx.doi.org/10.4103/2152-7806.90692

[36] Takagi, Y., Kikuta, K., Nozaki, K. and Hashimoto, N. (2010) Early Regrowth of Juvenile Cerebral Arteriovenous Malformations: Report of 3 Cases and Immunohistochemical Analysis. World Neurosurgery, 73, 100-107. http://dx.doi.org/10.1016/j.surneu.2009.07.008

[37] Liu, S., Sammons, V., Fairhall, J., Reddy, R., Tu, J., Hong Duong, T.T. and Stoodley, M. (2012) Molecular Response of Brain Endothelial Cells to Radiation in a Mouse Model. Journal of Clinical Neuroscience, 19, 1154-1158. http://dx.doi.org/10.1016/j.jocn.2011.12.004

[38] Cheng, Y., Dai, Q., Morshed, R.A., Fan, X., Wegschied, M.L., Wainwright, D.A., et al. (2014) Blood-Brain Barrier Permeable Gold Nanoparticles: An Efficient Delivery Platform for Enhanced Malignant Glioma Therapy and Imaging. Small, 10, 5137-5150. http://dx.doi.org/10.1002/smll.201400654

[39] Jain, S., Hirst, D.G. and O’Sullivan, J.M. (2012) Gold Nanoparticles as Novel Agents for Cancer Therapy. The British Journal of Radiology, 85, 101-113. http://dx.doi.org/10.1259/bjr/59448833

[40] Gale, N.W. and Yancopoulos, G.D. (1999) Growth Factors Acting via Endothelial Cell-Specific Receptor Tyrosine Kinases: VEGFs, Angiopoietins, and Ephrins in Vascular Development. Genes \& Development, 13, 1055-1066. http://dx.doi.org/10.1101/gad.13.9.1055

[41] Fontanella, C., Ongaro, E., Bolzonello, S., Guardascione, M., Fasola, G. and Aprile, G. (2014) Clinical Advances in the Development of Novel VEGFR2 Inhibitors. Annals of Translational Medicine, 2, 123.

[42] Smyth, E.C., Tarazona, N. and Chau, I. (2014) Ramucirumab: Targeting Angiogenesis in the Treatment of Gastric Cancer. Immunotherapy, 6, 1177-1186. http://dx.doi.org/10.2217/imt.14.85

[43] Zhou, D., Zhan, S., Zhou, D., Li, Z., Lin, X., Tang, K., et al. (2011) A Study of the Distribution and Density of the VEGFR-2 Receptor on Glioma Microvascular Endothelial Cell Membranes. Cellular and Molecular Neurobiology, 31, 687-694. http://dx.doi.org/10.1007/s10571-011-9665-6

[44] Jabbour, M.N., Elder, J.B., Samuelson, C.G., Khashabi, S., Hofman, F.M., Giannotta, S.L., et al. (2009) Aberrant Angiogenic Charactheristics of Human Brain Arteriovenous Malformation Endothelial Cells. Neurosurgery, 64, 139-146. http://dx.doi.org/10.1227/01.NEU.0000334417.56742.24

[45] Uranishi, R., Baev, N.I., Ng, P.Y., Kim, J.H. and Awad, I.A. (2001) Expression of Endothelial Cell Angiogenesis Receptors in Human Cerebrovascular Malformations. Neurosurgery, 48, 359-367.

[46] Koizumi, T., Shiraishi, T., Hagihara, N., Tabuchi, K., Hayashi, T. and Kawano, T. (2002) Expression of Vascular Endothelial Growth Factors and Their Receptors in and around Intracranial Arteriovenous Malformations. Neurosurgery, 50, 117-124.

[47] Hatva, E., Jääskeläinen, J., Hirvonen, H., Alitalo, K. and Haltia, M. (1996) Tie Endothelial Cell-Specific Receptor Tyrosine Kinase is Upregulated in the Vasculature of Arteriovenous Malformations. Journal of Neuropathology \& Experimental Neurology, 55, 1124-1133. http://dx.doi.org/10.1097/00005072-199611000-00003

[48] Bai, J., Wang, Y.L., Liu, L. and Zhao, Y.L. (2014) Ephrin B2 and EphB4 Selectively Mark Arterial and Venous Vessels in Cerebral Arteriovenous Malformation. Journal of International Medical Research, 42, 405-415. http://dx.doi.org/10.1177/0300060513478091

[49] Corre, I., Guillonneau, M. and Paris, F. (2013) Membrane Signalling Induced by High Doses of Ionizing Radiation in the Endothelial Compartment. Relevance in Radiation Toxicity. International Journal of Molecular Sciences, 14, 22678-22696. http://dx.doi.org/10.3390/ijms141122678

[50] Li, J., Huang, S., Armstrong, E.A., Fowler, J.F. and Harari, P.M. (2005) Angiogenesis and Radiation Response Modulation after Vascular Endothelial Growth Factor Receptor-2 (VEGFR2) Blockade. International Journal of Radiation Oncology, Biology, Physics, 62, 1477-1485. http://dx.doi.org/10.1016/j.jjrobp.2005.04.028

[51] Kim, G.H., Hahn, D.K., Kellner, C.P., Hickman, Z.L., Komotar, R.J., Starke, R.M., et al. (2008) Plasma Levels of Vascular Endothelial Growth Factor after Treatment for Cerebral Arteriovenous Malformations. Stroke, 39, $2274-2279$. http://dx.doi.org/10.1161/STROKEAHA.107.512442

[52] Vernimmen, F.J. (2014) Vascular Endothelial Growth Factor Blockade: A Potential New Therapy in the Management of Cerebral Arteriovenous Malformations. Journal of Medical Hypotheses and Ideas, 8, 57-61. http://dx.doi.org/10.1016/j.jmhi.2013.10.001

[53] Ngwa, W., Makrigiorgos, G.M. and Berbeco, R.I. (2012) Gold Nanoparticle Enhancement of Stereotactic Radiosurgery for Neovascular Age-Related Macular Degeneration. Physics in Medicine and Biology, 57, 6371-6380. http://dx.doi.org/10.1088/0031-9155/57/20/6371

[54] Rahman, W.N., Corde, S., Yagi, N., Abdul Aziz, S.A., Annabell, N. and Geso, M. (2014) Optimal Energy for Cell Radiosenstivity Enhancement by Gold Nanoparticles Using Synchrotron-Based Monoenergetic Photon Beams. International Journal of Nanomedicine, 19, 2459-2467. http://dx.doi.org/10.2147/IJN.S59471 